\title{
The Axisymmetric Extrusion of Solid Chocolate and the Effect of Die Geometry
}

\author{
Nita C. Mulji - Malcolm R. Mackley \\ Department of Chemical Engineering \\ University of Cambridge \\ New Museums Site \\ Pembroke Street \\ Cambridge, CB2 3RA, UK \\ mrm1@cheng.cam.ac.uk
}

\begin{abstract}
This paper investigates some of the effects of axisymmetric die geometry and flowrate during the isothermal extrusion of solid chocolate. Experimental observations, such as the material exhibiting a yield stress, flowrate independence and irreversible deformation, indicate that solid chocolate can be modelled using a rigid perfect plastic constitutive model (usually applied to the characterisation of metal forming processes). Numerically obtained extrusion pressures for a range of area reductions, using a commercial finite element package (ABAQUS) in combination with a remeshing code, are compared to experimental data to determine the uniaxial yield stress of the material. Analytical approximations are used to verify the numerical results. A study of the material behaviour in the die land, however, shows that the perfect plastic description can be inadequate in predicting extrusion pressures under certain conditions.

KEYWORDS: Axisymmetric Extrusion, Die Geometry, Plastic, Chocolate, Finite Element Modelling and ABAQUS.
\end{abstract}

International Journal of Forming Processes. Volume 6 - No. 2/2003, pages 161 to 177 


\section{Introduction}

Extrusion processing is commonly used to form materials into products or intermediates with a fixed cross-sectional shape, for example in the production of sections (for car bodies) and tubes (for piping) from metals. The process is characterised by material filled in a barrel being forced through an area reduction (die). Ram (or piston) extruders are the simplest devices, where the positive displacement of the piston provides the driving force required for the extrusion (Figure 1). These extruders are typically used for either rheological characterisation or for small-scale production.

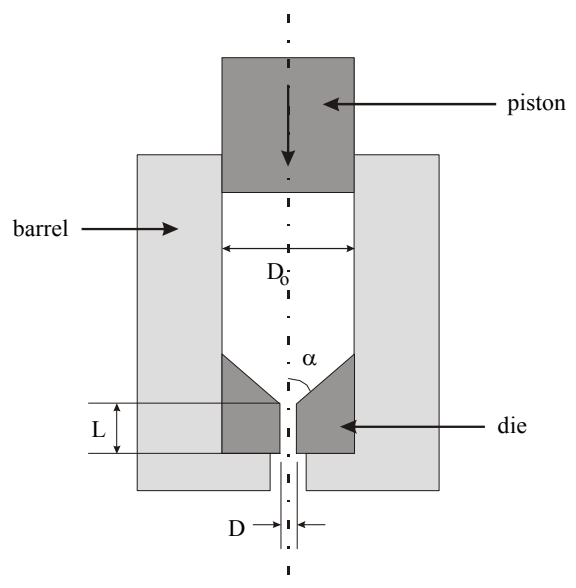

$\alpha \quad$ die entry angle

$\mathrm{D}_{\mathrm{o}}$ barrel diameter

D die exit diameter

L die land length

Figure 1. A ram extruder with an axisymmetric die, at the barrel base

Extrusion can also be applied to foodstuffs, for example sugar products containing various fat components [TOD 88] and ice cream [BIN 96]. Chocolate products however are usually made by pouring molten chocolate onto a sweet centre or into a mould [BEC 99]. In 1992, Mackley showed that solid chocolate could be extruded isothermally and that for a period of time after extrusion the extrudate retained the ability to undergo plastic deformation [MAC 92]. The extrusion processing of solid chocolate has made it possible to produce continuous lengths of shapes of various complexities by simply changing the die geometry (Figure 2).

The prediction of the optimum flow channel geometry for non-trivial shapes (that minimise the extrusion power and extrudate defects) is complicated. Consequently, die design at present is essentially a trial and error operation. To obtain a satisfactorily shaped extrudate, the material must exit the die with a uniform velocity across its section. This depends on parameters such as material rheology, flow channel geometry and processing rate. 


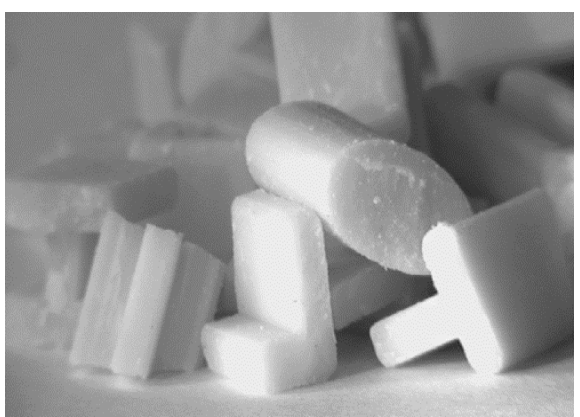

Figure 2. White chocolate shapes, no larger than $1 \mathrm{~cm}^{2}$ in cross-sectional area, formed by solid state extrusion followed by cutting

The rigid perfect plastic constitutive model is used here to describe the rheology of chocolate, as it exhibited a yield stress, deformed irreversibly with no visible elastic deformation and showed no flowrate dependence [BEC 94]. The main properties that define plastic behaviour are an irreversible deformation, which may be practically independent of strain rate, and the existence of a limit stress, which is the transition between elastic and plastic deformation. For a perfect plastic material, the limit stress is independent of the loading or deformation history of the material, whereas a non-perfect plastic material may exhibit hardening behaviour, where the limit stress increases with previous deformation (normally attributed to strain induced structuring). For a rigid plastic material, the elastic component of strain is disregarded and the material is assumed to remain rigid when stressed below the yield point. Therefore, the elastic modulus has an infinitely large value, and so the stress field in the rigid region is indeterminate. In general, a yield criterion describes the limit of elasticity under any possible combination of stresses. The limit surface for a three-dimensional model is written as $\mathrm{f}(\sigma)=0$, where $\sigma$ is the stress tensor. For metals, yielding occurs when some scalar function of the principal stress $\left(\sigma_{i}\right)$ differences reaches a critical magnitude. If there is no work hardening and the yield surface is not affected by hydrostatic pressure, the tensile yield stress must be a constant, whose value is incorporated in the chosen yield criteria. The von Mises yield criterion [1] is used in this paper, where $\mathrm{Y}$ is the uniaxial yield stress.

$$
\left(\sigma_{1}-\sigma_{2}\right)^{2}+\left(\sigma_{2}-\sigma_{3}\right)^{2}+\left(\sigma_{3}-\sigma_{1}\right)^{2}=2 \mathrm{Y}^{2}
$$

The rigid perfect plastic model requires only one material parameter, the uniaxial yield stress Y, for complete rheological characterisation. This parameter is normally evaluated from uniaxial tensile tests [CAL 85]. However, it is not possible to use this mechanical test on chocolate due to its brittle nature. In this paper, the experimental extrusion pressures for axisymmetric dies are used to establish the uniaxial yield stress. This is achieved by scaling the extrusion pressures obtained using the plasticity model for axisymmetric orifice dies with a range of area reductions to the experimental results, by adjusting the uniaxial yield stress. Here we 
also investigate the effect of axisymmetric die geometry on the extrusion pressure and material behaviour.

\section{Numerical analysis}

Exact solutions to the plasticity equations are not available for axisymmetric die geometries, and so a numerical solution procedure was employed. ABAQUS v 5.5, a finite element package, was used to evaluate extrusion pressures. The container walls were assumed to be smooth, as the extrusion pressure from the work done against friction upstream of the die exit is small in comparison to the mechanical work dissipated in deforming the material. However, the extrusion pressure contribution from the die land may be comparable to the die entry contribution, as in the extrusion processing of polymers, for example. Therefore, this particular set of numerical solutions is only applied to experimental results obtained using orifice dies (dies with no land).

In a typical axisymmetric extrusion analysis, only one half of a longitudinal section taken through the centre line of the extruder barrel is defined due to the symmetry of the problem, and axisymmetric material elements are used. The material in the barrel and die is represented by a material billet that is defined by a mesh of elements. An incremental Lagrangian analysis was performed in which the material was assumed to be isotropic and incompressible. Axisymmetric extrusion analyses were performed for orifice dies with an entry angle of $45^{\circ}$, which is the same angle as that used for the experimental studies, for evaluating the uniaxial yield stress. Each analysis was started with the material billet upstream of the die entry. A constant downward velocity boundary condition was then applied to the top surface of the billet, and extrusion pressure data were collected as the billet passed through the die. The analysis was performed in a number of time steps, whose length could be defined by the user. Each time step consisted of a number of increments. ABAQUS first made an initial guess for the displacements undergone by the nodes during a time increment, and the strain increments were calculated throughout the material. At the end of the time increment, the stress increments were calculated from the strain increments using the constitutive model. If the force equilibrium equations were sufficiently satisfied throughout the material, then the next time increment began. However, if the relationship was not satisfied to a sufficient degree, then the nodal displacements were adjusted repeatedly until equilibrium was obtained. At the end of each time step, the extrusion pressures for all the increments in the step were sent to a data file. Once the process reached equilibrium, the extrusion pressure was obtained by averaging over a number of time increments.

During preliminary analyses, a rectangular mesh was used and large strain deformations and mesh degeneration were encountered at the die entry, which resulted in large oscillations of the extrusion pressure during steady state. These problems were overcome by using a remeshing code, developed by Horrobin 
[HOR 99], in combination with ABAQUS. This allowed the use of a quadrilateral mesh with small element sizes concentrated in regions where large strain rates occurred, namely near the die entry and exit (Figure 3). The die entry and exit corners of the die were rounded slightly (with a radius 10 times the size of the smallest element) to avoid elements crossing the die wall boundary. Thus, computational time was reduced as the extrusion problems could be run with fewer elements. The mesh generation procedure is described in Horrobin [HOR 99]. At the end of each time step, the distorted mesh could be replaced with a new mesh produced by remeshing, where the old solution was mapped onto the new mesh. About 300 elements were required for area reductions, , of 0.75-0.95 and 1000 elements for area reductions larger than 0.95. Thus, Rereasing the die area reduction increased computational time significantly. Each time increment step required about 20 minutes and up to 400 steps were required for a steady state solution, using a $170 \mathrm{MHz}$ Sparc Ultra 2.

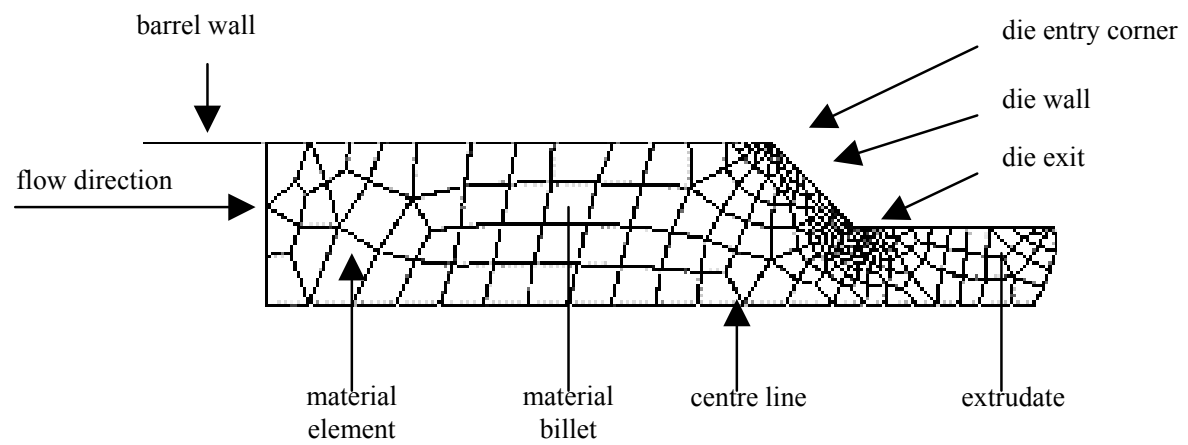

Figure 3. Typical quadrilateral mesh used for the axisymmetric orifice die extrusion problems showing concentration of elements at the die entry and exit $\left(45^{\circ}\right.$ entry angle)

Figure 4 shows a typical extrusion pressure trace obtained during an analysis that used remeshing, where the dimensionless extrusion pressure (the extrusion pressure divided by the uniaxial yield stress) is plotted against time. The numerical extrusion pressures presented in this paper have been obtained from such traces.

To validate the numerical extrusion pressures, they were compared to extrusion pressures obtained from analytical approximations for axisymmetric orifice dies. In plasticity theory, two theorems enable forming loads to be calculated approximately. The two load values obtained are different in general, with the stress field approach always resulting in an underestimate of the actual load value (lower bound theorem) and the velocity field approach in an overestimate (upper bound theorem) [CAL 85]. In the lower bound approach, a stress field is constructed such that the equilibrium equations and yield condition are satisfied and the load is obtained without consideration of the mode of deformation. In contrast, in the upper bound approach 
the load is calculated from a proposed mode of deformation through an energy balance, without consideration of the equilibrium condition. An upper bound model is one of the methods used to check the numerical results, as a number of solutions were available in the literature. Solutions to the lower bound theorem were not as readily available for extrusion problems, and so the ideal work equation is also used to check the numerical results. The upper bound and the ideal work results should bound the actual extrusion pressure obtained from the numerical results, as the former is an overprediction and the latter an underprediction of the actual extrusion pressure.

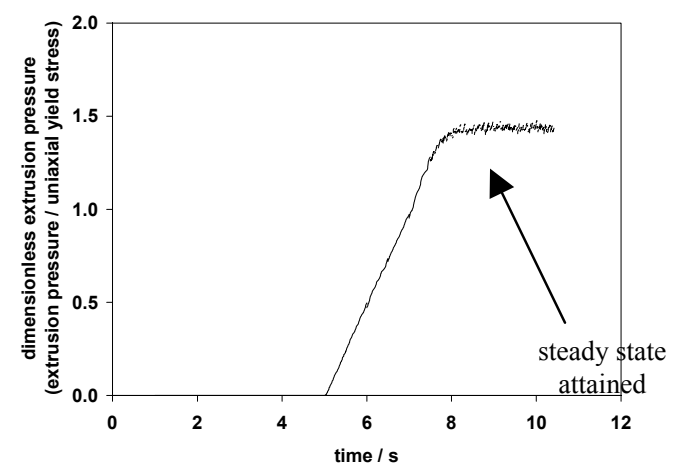

Figure 4. A typical dimensionless extrusion pressure against time trace obtained in an ABAQUS analysis that used remeshing

\section{Theoretical approximations}

\subsection{The upper bound approach}

Calladine [CAL 85] presents a relatively simple result for the extrusion pressure $\mathrm{P}_{\mathrm{E}}$ associated with tapered entry axisymmetric dies using the upper bound theorem. Figure 5 shows the deformation mode used by Calladine, which is based on a velocity field proposed by Kobayashi \& Thomsen [KOB 65].

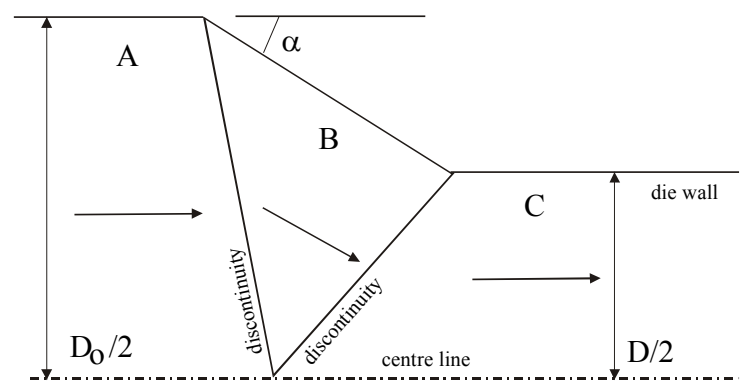

Figure 5. A postulated deformation mode for axisymmetric extrusion through a tapered entry die [CAL 85] 
The velocity vector is parallel to the die face everywhere and the container walls are assumed to be smooth. In an axisymmetric process, the circumference of a material element flowing through the die decreases, and so block $\mathrm{B}$ cannot be considered to slide rigidly along the die face. B is separated from the rigid blocks A and $\mathrm{C}$, which travel in the axial direction but with different velocities, by conical velocity discontinuities. These interfaces remain stationary with respect to the dies, and must intersect with the die where there is a discontinuity in the slope of that surface. Energy dissipation occurs when the material traverses the interfaces. Calladine presents an expression for the extrusion pressure $\mathrm{P}_{\mathrm{E}}$ based on Figure 4 (equation [2]), where $\mathrm{s}$ is equal to $\mathrm{D} / \mathrm{D}_{0}$. Extrusion pressures for axisymmetric orifice dies (entry angle of $45^{\circ}$ ) are obtained using equation [2] for a range of area reductions that encompasses those used experimentally.

$$
\begin{aligned}
& \mathrm{P}_{\mathrm{E}}=\mathrm{Y}\left(\frac{1+\mathrm{s}}{\sqrt{\mathrm{s}} \sin \alpha}-2 \cot \alpha\right)+\mathrm{Y}\left(\frac{1}{2 \sin \alpha}\left(\frac{1}{\sqrt{\mathrm{s}}}+\sqrt{\mathrm{s}}+2 \cos \alpha \ln (\cos \alpha)\right)-\cot \alpha\right) \\
& +\mathrm{Y} \ln \left(\frac{1}{\mathrm{~s}}\right)
\end{aligned}
$$

\subsection{The ideal work equation}

The ideal work equation, initially developed for wire drawing, can be used as a lower bound to the pressure difference across the die entry [JOH 83]. It gives the minimum work required to change the cross-sectional area of a sample by a specified amount. For an isotropic perfect plastic material undergoing homogeneous uniaxial tensile deformation, at constant volume, the pressure difference across the entry of the die is given by equation [3], where $\mathrm{A}_{0}$ is the initial cross sectional area and $\mathrm{A}$ is the cross sectional area after deformation.

$$
\mathrm{P}_{\mathrm{E}}=\mathrm{Y} \ln \frac{\mathrm{A}_{0}}{\mathrm{~A}}
$$

\section{Experimental procedure}

\subsection{Material}

The milk chocolate used in this research contains $47 \mathrm{wt} \%$ sugar, $17 \mathrm{wt} \%$ non-fat milk solids, $14 \mathrm{wt} \%$ cocoa mass, $8 \mathrm{wt} \%$ cocoa butter, $8 \mathrm{wt} \%$ milk fat and $6 \mathrm{wt} \%$ other. As the extrusion pressure is independent of feed size and physical form, solid granules of chocolate were used as the feed for the extrusion process. 


\subsection{Extrusion process}

A Davenport capillary rheometer was used for the extrusion experiments (Figure 6). It is a constant velocity, vertical, batch extruder. A Grant LD20 ethylene-glycol circulator unit supplied fluid to a cooling jacket that surrounded the barrel and die holder and was used to bring the barrel wall, die and feed temperature to $20^{\circ} \mathrm{C}$. The removable die holder, at the bottom of the barrel, could hold dies with an outer diameter less than $20 \mathrm{~mm}$ (restricted by the barrel internal diameter) and height less than $35.6 \mathrm{~mm}$ (position of the transducer upstream). Brass orifice dies with an entry angle of $45^{\circ}$ and a flowrate of $0.785 \mathrm{~cm}^{3} \mathrm{~s}^{-1}$ were used unless stated otherwise.

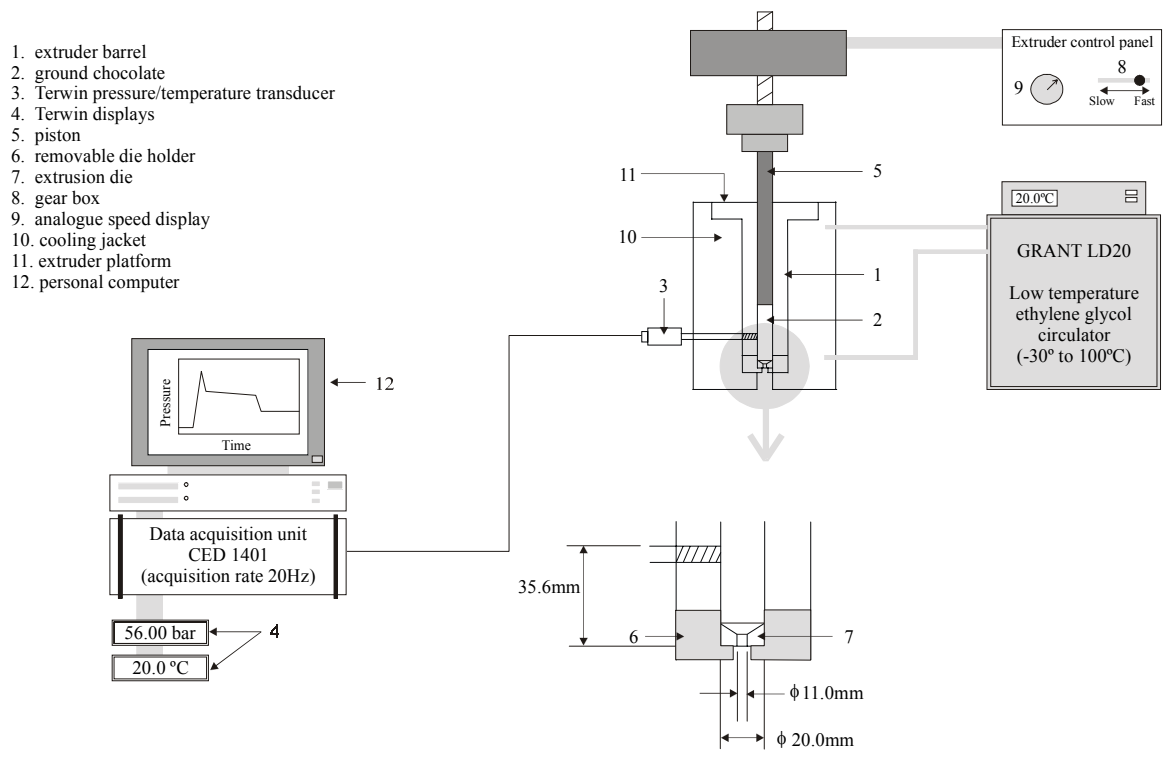

Figure 6. Extrusion equipment schematic

A pressure transducer, either one with a range of $0-35 \mathrm{MPa}$ or another with a range of 0-70 MPa, was used to measure the extrusion pressure as appropriate. The sensing head of the transducer was positioned $35.6 \mathrm{~mm}$ upstream of the die entry. The pressure difference between the transducer port and the die entry was found experimentally to be negligible compared to that across the die. The transducer output varied linearly with pressure and, suitably amplified, was transmitted to a CED 1401 interface where readings were logged at a rate of $20 \mathrm{~Hz}$ into a PC running CHART, a data recording package. CHART was used to log pressure as a function of time, and to evaluate the mean extrusion pressure. An example of the variation of the extrusion pressure with time typically observed during a batch experiment is shown in Figure 7. 


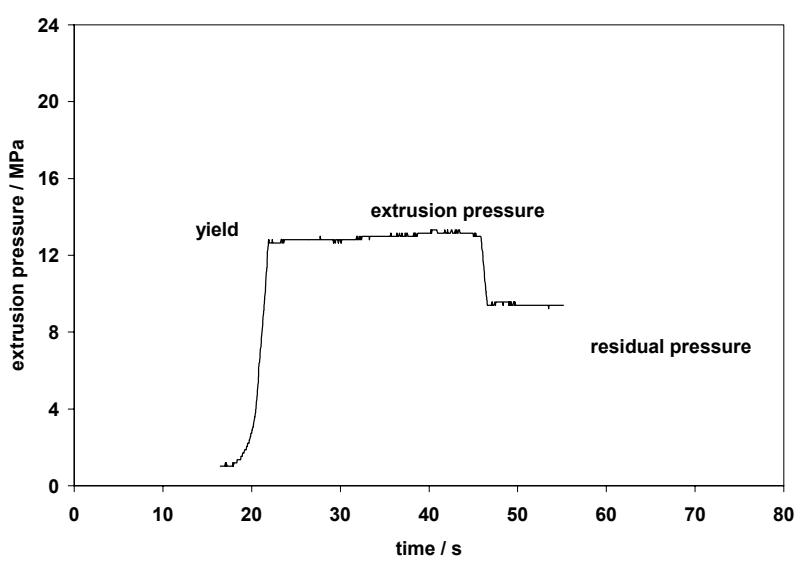

Figure 7. Typical pressure-time trace for a batch extrusion

Initially, the material is compacted forming a chocolate billet and the extrusion pressure rises but no flow occurs until the yield point, after which steady flow begins. When the piston stops, there is an instantaneous relaxation to a residual pressure. The lower/upper error bars in this paper represent the average of the minimum/maximum extrusion pressure from a number of experiments within the steady flow region.

\section{Results}

\subsection{Orifice dies}

To confirm that the rate-independent behaviour reported by Beckett et al. [BEC 94] under similar conditions is observed over a wider range of area reductions and flowrates, experiments with three die area reductions were performed. The experimental extrusion pressure was independent of extrusion speed for each of the area reductions studied (Figure 8). This rate independent behaviour at each area reduction confirmed that the perfect plastic material model (a rate-independent model) was appropriate for chocolate within this range of area reductions and flowrates for orifice dies.

To test whether the assumption of the container walls being smooth in the numerical and analytical approximations is acceptable, experiments with orifice dies with varying entry angles for two area reductions were performed. Figure 9 is a plot of extrusion pressure against entry angle for dies with exit diameters of 1 and $4 \mathrm{~mm}$. The experimental extrusion pressures were essentially independent of entry angle for both the area reductions studied. Thus, the extrusion pressure contribution from the 
work done against friction at the die entry wall is small in comparison to the mechanical work dissipated in deforming the material.

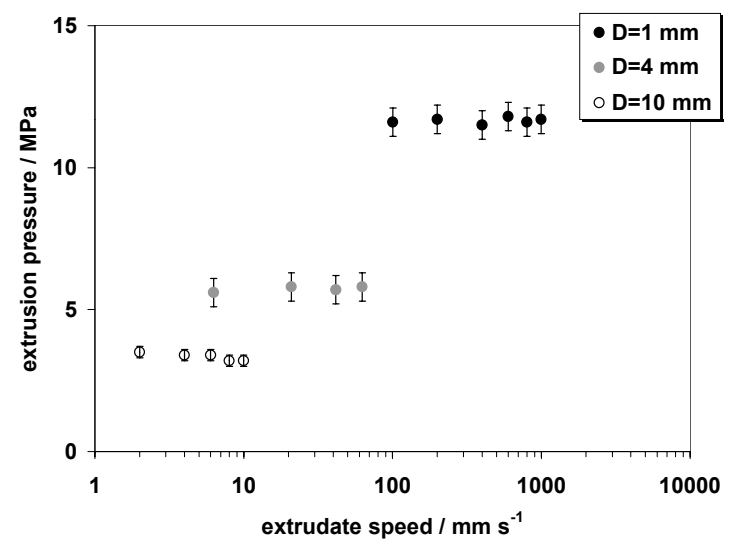

Figure 8. Experimental extrusion pressure against extrudate speed for three die exit diameters (orifice dies)

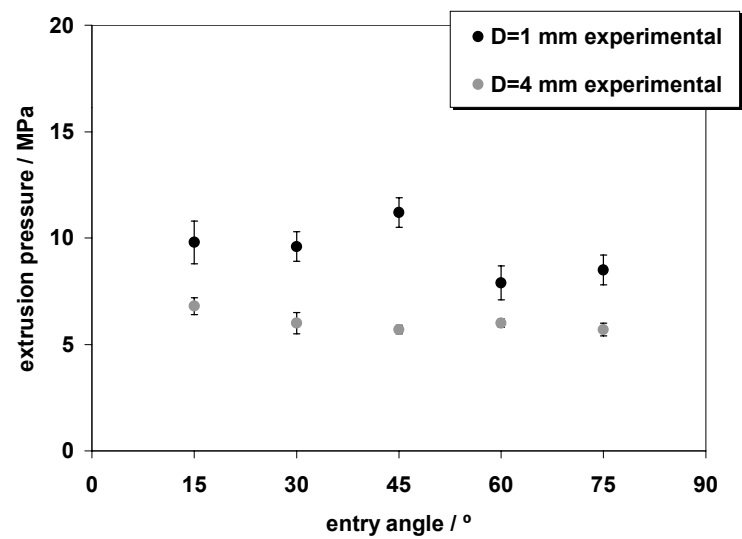

Figure 9. Experimental extrusion pressure against entry angle for two die exit diameters (orifice dies)

To evaluate the uniaxial yield stress, numerical analyses were performed for a range of area reductions. In Figure 10a, the dimensionless extrusion pressure (extrusion pressure/uniaxial yield stress) is plotted against $\ln \mathrm{D}_{0} / \mathrm{D}$. The numerical extrusion pressures lie between the ideal work and upper bound extrusion pressures, thus supporting the numerical solutions obtained. As the extrudate in the numerical 
analyses became narrower with increasing area reduction, smaller elements were required. Hence, the number of elements used in the numerical analyses increased from 300 elements, for the smallest area reduction, to 1000 for the largest. The remeshing code enabled the successful simulation of axisymmetric extrusion problems of up to 400:1 in area reduction.

[a]

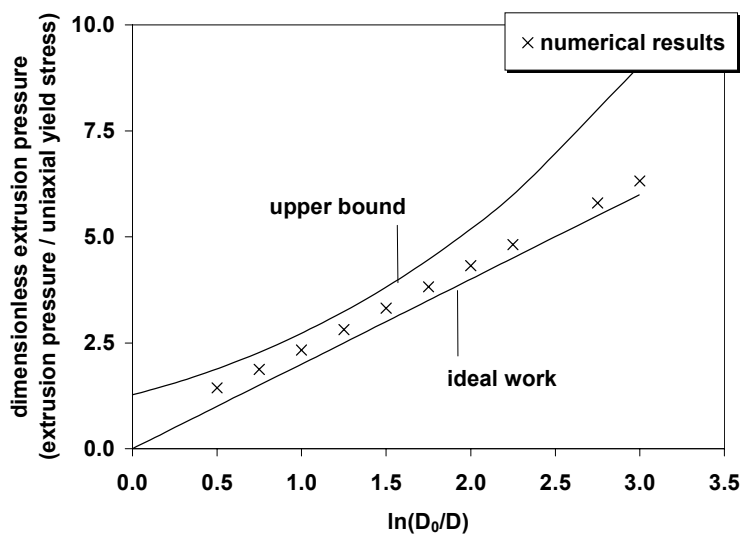

[b]

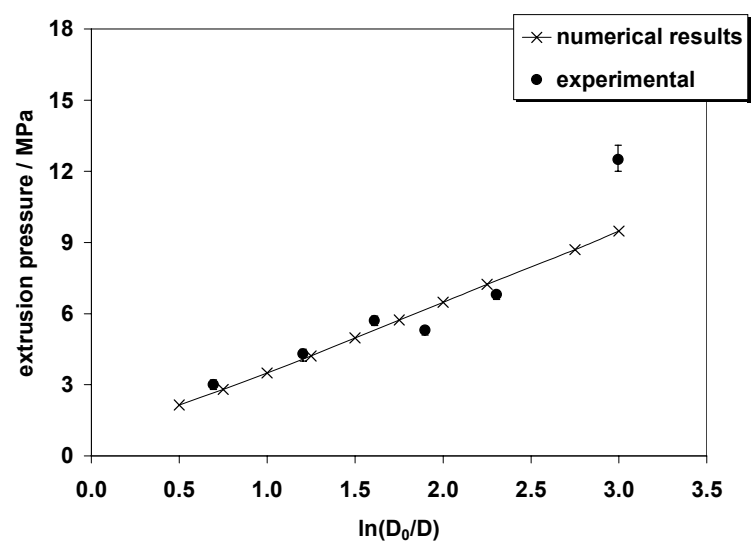

Figure 10. Extrusion pressures against $\ln D_{0} / D$ (orifice dies) [a] dimensionless $A B A Q U S$ results verified using the ideal work and upper bound approximations to the extrusion pressure [b] scaled ABAQUS results $(Y=1.5 \mathrm{MPa})$

In Figure 10b, the experimental and numerical extrusion pressures have been plotted against $\ln \mathrm{D}_{0} / \mathrm{D}$. For the experiments, orifice dies with exit diameters of 1,2 , $3,4,6$ and $10 \mathrm{~mm}$ were used and a flowrate of $0.785 \mathrm{~cm}^{3} \mathrm{~s}^{-1}$. The numerical model has been scaled to the experimental data using a uniaxial yield stress of 
$1.5 \mathrm{MPa} \pm 0.1 \mathrm{MPa}$ (the deviation represents the error in the evaluation of the uniaxial yield stress from the experimental data). This model fits the experimental data well except at the large logarithmic reduction ratio of 3 , where the numerical model underpredicts by about $28 \%$. This anomaly is discussed further in the next section.

\subsection{Dies with die land}

The wall boundary conditions in the die land were evaluated using dies with a range of area reductions. Axisymmetric dies with exit diameters of 1, 2, 3, 4, 6 and $10 \mathrm{~mm}$ and land lengths of $0,10,20$ and $30 \mathrm{~mm}$ were used. During the experiments, the pressure transducer was positioned just above the die entry, hence the pressure difference across the die was measured, which is the sum of the entry $\mathrm{P}_{\mathrm{E}}$ and land $\mathrm{P}_{\mathrm{L}}$ pressure differences. To study the flow of the material in the land, it was necessary to evaluate the pressure difference across the land. Therefore, the entry pressure difference was subtracted from the extrusion pressure to give the land pressure difference. In the present work, entry pressure differences have been found experimentally using orifice dies, and the extrusion pressure was assumed to be a sum of the entry and land pressure differences.

It is possible to model the die land pressure difference based on the Coulomb friction law [4] for contact between solid bodies [MIC 92]. This is appropriate when the wall shear stress at a point a fixed distance from the land entry is a function of the land length, where $\mu$ is the Coulomb friction coefficient. Note that the material is assumed to slip at the wall.

$$
\mathrm{P}_{\mathrm{L}}+0.1=0.1 \exp \left(\frac{4 \mu \mathrm{L}}{\mathrm{D}}\right)
$$

This equation can be used to model the experimental data and to obtain a value for the Coulomb friction coefficient. For dies with exit diameters of 4, 6 and $10 \mathrm{~mm}$, the experimental data for $\mathrm{P}_{\mathrm{L}}+0.1 \mathrm{MPa}$ are plotted against land length in Figure 11a. From Figure 11a, the Coulomb friction coefficient was found to be 0.11, 0.16 and 0.26 for the dies with 4, 6 and $10 \mathrm{~mm}$ exit diameters respectively.

It is believed that the bulk of the material flows as a rigid plug lubricated by a thin layer of liquid fat. The values of $\mu$ are not constant with area reduction, but are seen to decrease steadily with increasing area reduction. An increase in either or both shear heating at the wall (resulting in a liquid fat layer at the wall that steadily decreases in viscosity with increasing area reduction) and bulk shear heating effects (increasing the liquid fat content of the material) could explain this apparent reduction in frictional resistance. 
[a]

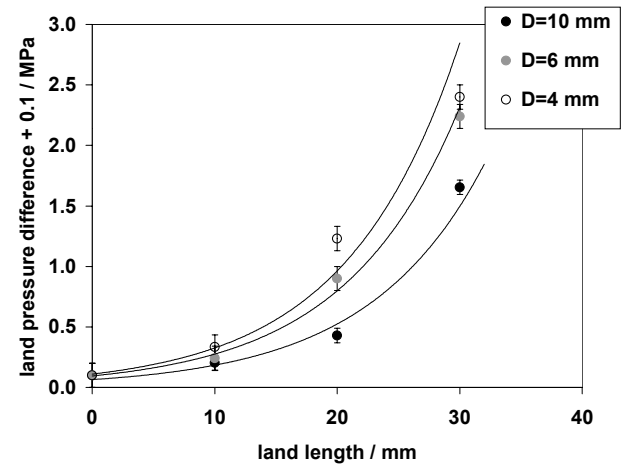

[b]

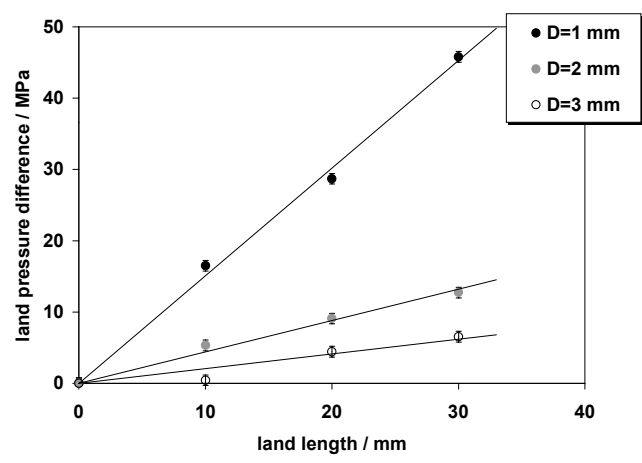

Figure 11. Experimental land pressure difference data plotted against land length [a] for 4, 6 and $10 \mathrm{~mm}$ exit diameter dies, also fitted with exponential functions for evaluating the Coulomb friction coefficient [b] for 1, 2 and $3 \mathrm{~mm}$ exit diameter dies, also fitted with linear functions for evaluating the wall shear stress

Figure $11 \mathrm{~b}$ is a sample plot of the variation of land pressure difference with land length for dies with exit diameters of 1,2 and $3 \mathrm{~mm}$, the larger area reduction dies. If the wall shear stress is constant, then a force balance on a section of the capillary (assuming a constant $\tau_{\mathrm{w}}$ boundary condition) gives the wall shear stress $\tau_{\mathrm{w}}$ [5]. The data sets have been fitted with linear functions to evaluate the wall shear stress. For the D equals 1,2 and $3 \mathrm{~mm}$ dies, $\tau_{\mathrm{w}}$ of $0.38,0.22$ and $0.15 \mathrm{MPa}$ were obtained respectively. These results are consistent with the model of a lubricating layer present at the land wall, such that the wall shear stress is independent of position along the land. The thickness of such a layer could increase with increasing area reduction, as more liquid fat is driven towards the die wall. It is possible that shearing is restricted to within this layer, while the bulk of the chocolate flowed as a rigid plug. If this was the case then flowrate dependence of the extrusion pressure could arise from any viscous deformation. 


$$
\tau_{\mathrm{w}}=\frac{\Delta \mathrm{PD}}{4 \mathrm{~L}}
$$

A series of experiments were performed to test this hypothesis, and a plot of extrusion pressure against extrudate speed is shown in Figure 12 for all dies with lands that showed flowrate dependence. Flowrate dependence of the extrusion pressure increased with both area reduction and land length. This dependence supports the model of a shearing layer at the wall. Note that no flowrate dependence was observed for the orifice dies. Figure 12a shows that for a land length of $30 \mathrm{~mm}$, the extrusion pressure was a function of flowrate for all reductions studied, including exit diameters of 4,6 and $10 \mathrm{~mm}$. Flowrate dependence became less significant at smaller area reductions, and was almost unnoticeable for the $D=6$ and $10 \mathrm{~mm}$ dies. With shorter land lengths $(10-20 \mathrm{~mm})$, only dies with the largest area reduction, $\mathrm{D}=1$ and $2 \mathrm{~mm}$, showed significant flowrate dependence (Figure 12b). Therefore, it is assumed that the dies with even smaller area reduction and land lengths would not show any flowrate dependence.

$[a]$

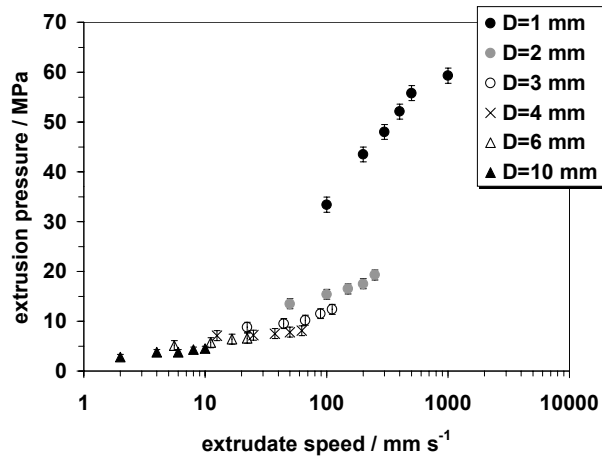

[b]

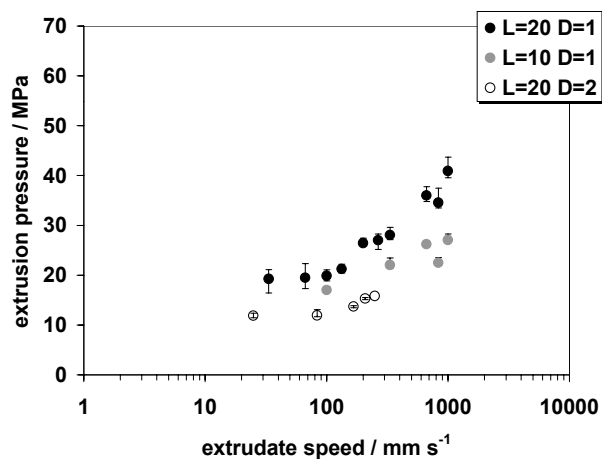

Figure 12. Extrusion pressure against extrudate speed for dies that showed flowrate dependence $[a] \mathrm{L}=30 \mathrm{~mm}$ dies $[\mathrm{b}] \mathrm{L}=10$ and $20 \mathrm{~mm}$ dies 
The effects of increasing die land length and area reduction on the material behaviour are consistent with an increase in the work done on the material causing an increase in the rate and extent of liquid fat migration and shear melting. Thus, for the small area reduction regime, a liquid fat layer is believed to become continuous and thicker along the land wall as area reduction is increased. This would explain the decreasing Coulomb friction coefficient observed. At some point, the absolute pressure and hence the work done on the chocolate become large enough for a layer of fat rich chocolate to begin shearing at the wall. It is believed that the liquid fat content of the shearing layer increases with area reduction. The transition between the two types of wall boundary condition is believed to be gradual and is observed to be around the area reduction of 0.96 , which corresponds to a die exit diameter of $4 \mathrm{~mm}$.

\section{Conclusion}

Initially, the rate independence of the extrusion pressure was experimentally verified using three orifice dies with different area reductions and testing them over a range of flowrates. This confirmed that the perfect plastic constitutive model was appropriate for modelling chocolate. Exact solutions to the plasticity equations are not available for axisymmetric die geometries however, and so ABAQUS was employed to obtain numerical solutions. The uniaxial yield stress was then determined to be $1.5 \mathrm{MPa}$, at $20^{\circ} \mathrm{C}$, by scaling the numerical extrusion pressures, obtained using the plasticity model for axisymmetric orifice dies with a range of area reductions, to the experimental results. An important aspect of this modelling was that only one adjustable material parameter was required, as materials such as polymers are commonly modelled using multiple adjustable parameters.

The numerical extrusion pressures lay between the ideal work and upper bound extrusion pressures, thus verifying the numerical solutions. In general, the numerical model agreed well with the experimental data, except at the large $\ln \left(\frac{\mathrm{D}_{0}}{\mathrm{D}}\right)$ value of 3, where the extrusion pressure was underpredicted. Possible explanations for this could be an increase in the contribution to the extrusion pressure from frictional resistance at the die entry wall or increased frictional contact between the particles or particle bridging at the die exit. In the present work, the mesh degeneration and extrusion pressure oscillation problems encountered during numerical simulations were successfully overcome by using a remeshing code, developed by Horrobin [HOR 99], in combination with ABAQUS. The results presented in this paper show that solid chocolate could be usefully modelled as an essentially rigid perfect plastic solid for a large range of area reductions.

For dies with die lands, the small area reduction regime $(\mathrm{D}=4,6$ and $10 \mathrm{~mm})$ was successfully modelled using Coulomb's friction law, which is appropriate when the wall shear stress at a point a fixed distance from the land entry is a function of 
the land length. It is believed that the bulk of the material flows as a rigid plug lubricated by a thin layer of liquid fat, hence a slip velocity wall boundary condition. The values of $\mu$ are not constant with area reduction, but are seen to decrease steadily with increasing area reduction. This is believed to be partly due to an increase in the liquid fat layer at the wall.

The large area reduction regime ( $\mathrm{D}=1,2$ and $3 \mathrm{~mm}$ ) was modelled with a constant wall shear stress, as experimentally observed. The wall shear stress values increased with increasing area reduction. It is believed that a rigid plug of material is surrounded by a shearing layer of liquid fat rich chocolate that is responsible for the flowrate dependence of the extrusion pressure observed with these dies. This dependence increased with both increasing area reduction and land length.

As the flowrate dependence of the extrusion pressure increased with increasing land length and area reduction (Figure 12), it is no longer accurate to use the perfect plastic description for this range of dies. It is then necessary to incorporate a viscous component into the constitutive model. This is the reason for the perfect plastic model under predicting the extrusion pressure in Figure 10 for the large area reduction die.

\section{Nomenclature}

\begin{tabular}{|c|c|c|}
\hline A & $\left(\mathrm{m}^{2}\right)$ & cross-sectional area \\
\hline $\mathrm{A}_{0}$ & $\left(\mathrm{~m}^{2}\right)$ & initial cross-sectional area \\
\hline $\mathrm{D}$ & (m) & die exit diameter \\
\hline $\mathrm{D}_{0}$ & (m) & barrel diameter (also taken as the die entry diameter) \\
\hline $\ln \left(\frac{\mathrm{D}_{0}}{\mathrm{D}}\right)$ & & logarithmic reduction ratio \\
\hline$\left(1-\frac{D^{2}}{D_{0}^{2}}\right)$ & & area reduction \\
\hline $\mathrm{L}$ & $(\mathrm{m})$ & die land length \\
\hline $\mathrm{P}_{\mathrm{E}}$ & $\left(\mathrm{Nm}^{-2}\right)$ & die entry pressure difference \\
\hline $\mathrm{P}_{\mathrm{L}}$ & $\left(\mathrm{Nm}^{-2}\right)$ & $\begin{array}{l}\text { pressure difference across the die land } \\
\text { D }\end{array}$ \\
\hline $\mathrm{Y}$ & $\left(\mathrm{Nm}^{-2}\right)$ & $\begin{array}{l}\overline{D_{0}} \\
\text { uniaxial (tensile) yield stress }\end{array}$ \\
\hline$\alpha$ & $\left({ }^{\circ}\right)$ & die entry angle \\
\hline$\mu$ & & Coulomb friction coefficient \\
\hline$\sigma$ & $\left(\mathrm{Nm}^{-2}\right)$ & stress tensor \\
\hline$\sigma_{\mathrm{i}}$ & $\left(\mathrm{Nm}^{-2}\right)$ & principal stress $[i=1,2$ or 3$]$ \\
\hline$\tau_{\mathrm{w}}$ & $\left(\mathrm{Nm}^{-2}\right)$ & wall shear stress \\
\hline
\end{tabular}




\section{Acknowledgements}

The authors would like to thank Nestlé Product and Technology Centre, York, UK for financial support, Dr Steve Beckett at Nestlé for his support and Dr D. J. Horrobin for the use of his remeshing code.

\section{References}

[BEC 99] BECKETT S. T., Industrial chocolate manufacture and use, third edition, Blackwell Science Ltd., Oxford, UK, 1999.

[BeC 94] Beckett S. T., Craig M. A., Gurney R. J., Ingleby B. S., Mackley M. R., PARSONS T. C. L., "The cold extrusion of chocolate", TransIChemE, Vol. 72, Part C, 1994, p. 47-54.

[BIN 96] BINLEY G. N., United States patent number 5,556,653, 1996.

[CAL 85] Calladine C. R., Plasticity for engineers, Ellis Horwood Ltd., UK, 1985.

[HOR 99] HorRobin D. J., Theoretical aspects of paste extrusion, doctoral Thesis, Department of Chemical Engineering, University of Cambridge, UK, 1999.

[JOH 83] Johnson W., Mellor P. B., Engineering plasticity, Ellis Horwood Ltd., UK, 1983.

[KOB 65] Kobayashi S., Thomsen E. G., "Upper- and lower bound solutions to axisymmetric compression and extrusion problems", International Journal of Mechanical Science, Vol. 7, 1965, p. 127-143.

[MAC 92] MACKLEY M. R., European Patent Number EP-A-0603467, 1992.

[MIC 92] Michaeli W., Extrusion dies for plastics and rubber, 2nd edition, Hanser publications, 1992.

[TOD 88] Todorova Z., Petrov T., Georgiev D., Asenova K., "Cold extrusion forming of sugar products”, Khranitela Promishlenost, Vol. 37 No. 4, 1988, p. 31-32.

Received: February $26^{\text {th }} 2002$

Revised: July $4^{\text {th }} 2002$

Nita Mulji obtained her MEng and PhD degrees from the Department of Chemical Engineering at Cambridge University, UK. Her research interests focus on material forming processes and the evolution of microstructure during processing.

Malcolm Mackley is the Professor of Process Innovation at the Department of Chemical Engineering at Cambridge University, UK. He heads a Polymer Fluids Group that has diverse interests in a range of materials and processes. 